Diana Heida Wolf has joined the faculty of the department of political science at Vassar College.

JAMES S. Young recently received his Ph.D. from Columbia University, where he has been promoted to an assistant professorship.

JAMrS V. Young has joined the faculty of the department of political science at St. Olaf College with the rank of assistant professor.

Joseph ZIKMUND will serve as an instructor in the department of political science at Duke University during the 1964-65 academic year.

Dina ZiNnes, department of government at Indiana University, has been promoted to the rank of assistant professor.

\title{
SUPPORT OF POLITICAL SCIENCE BY THE NATIONAL SCIENCE FOUNDATION
}

The success of the National Science Foundation in advancing basic research and education in the sciences requires clear communication and understanding with the individual scientists and groups that it supports. Recent questions by political scientists as to support of their field have resulted in a careful review by the staff of the Foundation and by the National Science Board of policies affecting support for the field of political science. The cooperation of the American Political Science Review is welcomed in distributing to members of the political science community this statement on National Science Foundation support for their field.

\section{Basic Research}

The Foundation is the only agency of the Federal Government that supports basic research in all the sciences. The lines among areas of research-conveniently grouped as basic, applied, and developmental-cannot always be sharply drawn. The Foundation, however, must establish policies on which to base its decisions of support to basic research and must work for an understanding of these by the individuals and groups with which we are cooperating to achieve our purpose. The Foundation does not itself conduct research or carry out educational projects.

The most important aspect of the Foundation's support of basic research is the awarding of funds for the work of individual investigators or groups of investigators on fundamental problems in all areas of science-the support of basic research projects. Facilities needed by the institutions at which the research is being conducted are another aspect of our basic research support. These include facilities and equipment of a specialized nature, required by particular fields, and facilities used for basic research and graduate education in all areas of the sciences. Another aspect of the Foundation's support of basic research is the dissemination of scientific informa- tion. In all these areas the Foundation's main consideration is whether the work that it supports contributes to the promotion of basic research.

Basic research in political science and other social sciences is interpreted as meaning research on problems that can be studied by methods that will yield independently verifiable results and that will produce results with general implications, rather than findings relevant principally to a particular time, place, or event. The Foundation will support research designed to elicit the scientific understanding of social processes and behavioral phenomena, but not studies designed to endorse particular social policies or to promulgate solutions of specific social problems.

The merit of research proposals is not judged by their promise of quick answers or of the immediate applicability of their results. The investigator is left free to concentrate on questions of scientific importance, irrespective of whether these be questions that require new data, the development or improvement of method, or the formation of theoretical models as a guide to empirical inquiry. Decisions on eligibility of proposals in the social sciences are governed by the desire to strengthen the social sciences as scientific disciplines, rather than by any proposed practical importance of the question chosen for study, or the immediate significance of results for political policy.

It is therefore clear that some research topics that may interest social scientists are not given research support by the National Science Foundation. Efforts to evaluate the merits of competing ideologies, political parties, interest groups, and other organizations are inappropriate for submission to the Foundation. In particular, the Foundation is not interested in polemics, doctrinaire pronouncements, or statements about public policy or controversial issues.

Research proposals in political science are handled by the National Science Foundation's Division of Social Sciences. The primary areas of 
social science support are cultural and physical anthropology, archaeology, demography, economics, geography, linguistics, political science, psychology, sociology, and the history and philosophy of science. In all instances the Division judges eligibility of proposals primarily in terms of one criterion: the potential contribution of the research to basic science. Within such limitations, investigators choose their own topics for research; proposals are not solicited and no particular research topics are given preferential review. The investigator is free to choose any methods of investigation, including quantitative, experimental, and other techniques, as long as they are scientific and appropriate to the projected study. The disciplinary identification of the proposer is irrelevant. Preliminary inquiries on the eligibility of a proposed research topic are invited. Details on application procedures are contained in a guide entitled "Grants for Scientific Research," which is available upon request from the National Science Foundation, Washington, D. C. 20550.

Proposals for the construction or remodeling of specialized facilities for research in political science or the acquisition of specialized research materials and equipment needed in this field are also handled by the Division of Social Sciences. Such examples might include, but are not limited to, specialized data repositories, field stations, specialized laboratories, and other forms of unique research space. Support of such facilities may include the purchase of equipment, the construction, conversion, renovation, or improvement of buildings, and the development of new means or devices for research.

The National Science Foundation's Division of Institutional Programs provides assistance for the renovation and construction of graduate science facilities in all the basic sciences, including political science. Proposals for support of facilities for basic research and research training may be submitted to the Division by institutions of higher education and related nonprofit research institutions. Funds are granted for such facilities as research and graduate training laboratories, supporting areas, animal buildings, and science libraries as part of science buildings. These facilities may house more than one scientific discipline, and have ranged from a grant to support the construction of a child development laboratory to a large high-rise building that will house a number of social science departments.

Science information activities which support basic research are administered by the NSF Office of Science Information Service and are directed toward developing new and/or improved methods for collecting, analyzing, controlling, storing, and disseminating scientific information and improving ex isting scientific information systems.

\section{Science Education}

National Science Foundation programs for education in the sciences are mainly at the graduate level where basic research is intimately involved in the education and training of first-class scientists and engineers. NSF educational support is offered through graduate fellowships, teachertraining institutes, the improvement of course content related to science teaching, and research participation opportunities.

Political scientists are eligible for support in the nine fellowship programs of the Foundation, which encompass all levels of study from graduate through senior postdoctoral, as follows:

Postdoctoral Fellowships primarily for individuals who have recently received a doctoral degree.

Senior Postdoctoral Fellowships primarily intended for recognized senior scientists.

Science Faculty Fellowships for junior college, college, and university teachers.

Summer Fellowships for Secondary School Teachers for the support of graduate level study in the field.

Senior Foreign Scientist Fellowships for nationals of foreign countries to engage in appropriate scientific programs at participating $\mathrm{U}$. S. universities.

NATO Postdoctoral Fellowships in Science, which each NATO country administers for its own nationals. On behalf of the Department of State, the National Science Foundation is responsible for administration of the program for the United States, including the selection of fellows.

Graduate Fellowships for students studying for a master's or a more advanced degree.

Cooperative Graduate Fellowships similar to graduate fellowships except that individuals apply through and are initially evaluated by the U. S. participating institutions which they expect to attend as fellows.

Summer Fellowships for Graduate Teaching Assistants for support of summer study in advanced degree programs.

It is hoped that the offer of NSF fellowship support will encourage applications at the postdoctoral level which reflect quantitative, objective, and verifiable approaches to the many areas encompassed in political science and its broad spectrum of sub-fields. The Foundation has adopted the following guidelines for political science (and all other supportable fields) in this year's fellowship programs:

In the postdoctoral and teacher-oriented programs, the Foundation will examine each application to determine the suitability of proposed programs of study and/or research in accordance 
with the guidelines set forth in the several program announcements.

In fellowship programs for graduate studentsGraduate, Cooperative Graduate, and Graduate Teaching Assistants-the Foundation will accept the graduate-level study program required by the degree-granting institution in fulfillment of the requirements for an advanced degree in political science. The Foundation recognizes that not all Graduate Schools have Departments of Political Science but nonetheless may offer advanced degrees in political science. It may therefore be necessary for the Foundation to make an individual determination of the acceptability of some degree programs for fellowship support.

In addition to its fellowship programs, the National Science Foundation supports a number of educational programs designed to provide instruction or experience in science to individuals ranging from secondary school students to senior scientists. Among these programs are institutes for the further training of school or college teachers, science course content improvement efforts, and participation in research by students and teachers. Proposals requesting support for such projects in political science will be accepted when the subject matter is to be treated scientifically, and here the same general principles will be applied as are set forth in the above discussion of basic research support. As in the case of research grants, science education grants and fellowships are made on the basis of merit without specific quotas for any field of science, institution, or geographic area. Further detailed information is available upon request from the Division of Scientific Personnel and Education, National Science Foundation.

Leland J. Haworth Director

National Science Foundation

Washington, D. C. 20550

August 26, 1964 